\section{The vital role of ventilation}

For dentists looking for ventilation advice, Vent-Axia is committed to improving indoor air quality and public health and has helped in the national response against COVID-19. The company can advise on a wide range of ventilation solutions that are ideal for dental surgeries depending on practice. Where dentists are keen to add extra airflow easily and quickly rather than upgrading a whole building system, consultants can consider adding commercial extract fans to increase fresh air.

Some dental practices may think upgrading ventilation is a big investment since installing a whole building ventilation system can cost in the region of $£ 10 \mathrm{k}$, making it prohibitive for some practices - but there are more affordable options on offer by opting for unitary ventilation. Extract/supply fans can simply be installed through a window or wall offering little disruption. For example, a traditional Vent-Axia T-Series window fan is available from as little as $£ 325.17$. The only other cost is the installation of the fan through a window - so for a relatively small investment, dentists can benefit from the ventilation result they need to reduce fallow time and so see more patients.

Vent-Axia's T-Series commercial fan offers high performance ventilation with low running costs. With both window
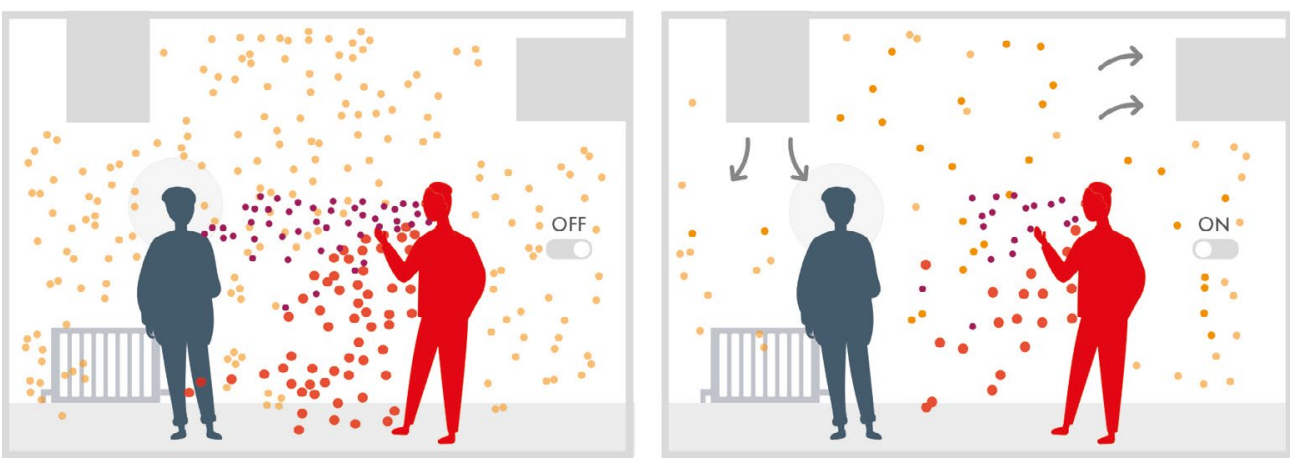

and wall options available, as well as Lo-Carbon models, it is both durable and reliable. Available with four sizes of extract/ intake fans and an easy fit connector Top Socket allowing fast and trouble-free mains connection, the T-Series is easy to install and replace. Alternatively, for ducted applications energy efficient ACM Mixed Flow In-Line fans offer quiet ventilation with two and a half times the pressure of conventional axial fans. Their compact design also makes them ideal for many ducted applications and they can operate in both horizontal and vertical positions.

For dentists wishing to upgrade ventilation in the whole building there are heat recovery or demand ventilation options. The Integra Heat recovery unit is ideal for smaller commercial applications up to $180 \mathrm{~m}^{2}$. With low power consumption and heat recovery, the unit extracts heat energy from the outgoing air and transfers this energy to the incoming fresh air tempering it, without the two air streams mixing. Meanwhile, D-ERV systems have sophisticated controls and sensors that can be used to easily adapt the system to the new COVID-19 requirements, providing ventilation appropriate to occupant needs. Vent-Axia’s Sentinel Totus D-ERV demand ventilation features low energy EC/ DC motors, up to $90 \%$ energy recovery and G4 replaceable synthetic filters, complete with filter change warning, and optional high grade F6 filters.

Vent-Axia has created a dedicated web page at https://www.vent-axia.com/ ventilation-in-dental-practices to inform and advise dental surgeries on the vital role of ventilation. For further information on all products and services offered by Vent-Axia telephone +44 (0)344 8560590 or visit www. vent-axia.com.

\title{
Affordable electric toothbrush with LED whitening technology
}

The UK's leading provider of non-peroxide natural teeth whitening products has launched the first affordable whitening toothbrush.

The first high performance electric toothbrush is the first of its kind with built in blue light whitening technology and is significantly cheaper than market rivals costing

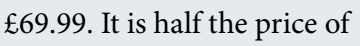
the cheapest rival and a third of the price of others.

The market has a number of similar devices which assist with teeth whitening but they are considerably more expensive, typically $£ 125-175$ and do not have the blue LED whitening lights in the head itself.

The low priced, high quality products come from Whites Beaconsfield, owned

by entrepreneurial brothers Ollie and Toby Brittan and their friend Tom Jansons.

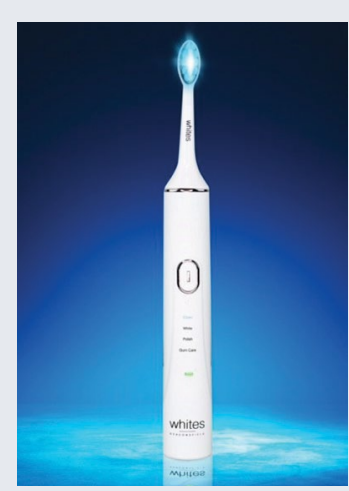

The new Whites Beaconsfield portable toothbrush safely and efficiently whitens teeth an average of 2.5 times shades in three days using state-of-theart LED blue light technology.

This powerful toothbrush paired with a preferred fluoride toothpaste of choice promotes cleaning and whitening in one convenient step.

The built-in LED blue light, alongside four interchangeable settings, is carefully tuned to wavelengths shown to further accelerate the whitening process without causing sensitivity, while also killing harmful bacteria to promote greater oral health.

The toothbrush set contains a USB cable for charging on the move (full charge lasts up to two weeks) and also two replaceable brush heads.

Whites Beaconsfield specialise in non-peroxide teeth whitening kits that can show results after just ten minutes and range in price from $£ 9.99$ to $£ 114.99$. The products vary from single items to ultimate teeth whitening kits (full product range www.whitesbeaconsfield.co.uk).

The extensively researched natural, vegan friendly oral care products are guaranteed to give cleaner teeth and a sparkly smile, naturally.

The non-peroxide alternative has been very successful because of the low cost convenient products which give great money back guarantee results without the use of peroxide.

Visit whitesbeaconsfield.co.uk for more details about the company and to browse the range of products. 